\title{
Reforming Tar from Biomass Gasification using Limonite and Dolomite as Catalysts
}

\author{
Hee Joon Kim* ${ }^{\dagger}$, Hiroo Kunii*, Liuyun $\mathrm{Li}^{*}$, Tadaaki Shimizu*, and Lae-Hyun Kim** \\ *Graduate School of Science and Technology, Niigata University, 2-8050 Ikarashi, Niigata, 950-2181, Japan \\ **Department of Chemical Engineering, Seoul National University of Science \& Technology, \\ Gongneung-2Dong, Nowon-Gu, Seoul, 139-743, Korea
}

(Received 14 October 2011, Revised 2 December 2011, Accepted 2 December 2011)

\begin{abstract}
In this study, Catalytic reforming with vapor and biomass gasification was simultaneously performed in a same fixed bed reactor at $600-800^{\circ} \mathrm{C}$. Light gases were produced from reformation of the tar (fuel gases) in biomass gasification by using limonite and dolomite, as catalysts. Hydrogen and carbon dioxide are main components in light gases. Hydrogen yields increased with temperature increasing in the range of $650-800^{\circ} \mathrm{C}$, because the water shift reaction was promoted by catalyst. The yield of hydrogen gas was increased about $160 \%$ under catalyst with the mixture of limonite and dolomite comparing to limonite only.
\end{abstract}

Key words : Biomass, Gasification, Catalyst, Hydrogen gas, fuel gas, limonite

\section{Introduction}

It is well known that biomass is one of the important primary and renewable energy sources because of carbon neutral energy. Furthermore, the utilization of biomass has been more and more concerned with the depletion of fossil fuel sources as well as the global warming issues. Gasification of biomass is one of the more promising techniques among all alternatives proposed for the production of energy from biomass. The gasification products contain methane, light hydrocarbon, tar and volatile alkali metals. Among them, the tar is a complex mixture of acid, aldehyde, ketone, alcohol, phenol, and aromatic hydrocarbon. The composition of the tar depends on the pyrolysis conditions [1]. Tar is an undesirable byproduct of biomass gasification because of the condensation and formation of tar aerosols, which presents significant impediment to the application of biomass gasification systems. Many researches about the decomposition of

\footnotetext{
${ }^{\dagger}$ To whom corresponding should be addressed.

Graduate School of Science and Technology, Niigata University, 2-8050 Ikarashi, Niigata, 950-2181, Japan

Tel./Fax : +81-25-262-7538; E-mail : kim@eng.niigata-u.ac.jp
}

tar have been done. Catalytic reforming or decomposition is one of the promising techniques for converting tar into useful gases. Many researches about catalytic decomposition of tar were carried out at $650-900^{\circ} \mathrm{C}$ using nickel based catalyst, because nickel based catalysts are very active in the decomposition of tars $[2,3]$. However deactivation of the catalysts due to carbon decomposition is a problem [4]. Furthermore, nickel compounds are expensive and toxic material, so the disposal of the used nickel catalysts is one of environmental problem. Therefore we have focused on natural limonite and dolomite ores as catalyst, which are inexpensive, abundant and non toxic. The main component of limonite is goethite $(\alpha-\mathrm{FeOOH})$. Goethite $(\alpha-\mathrm{FeOOH})$, itself, has a little activation in the decomposition of tars. However, goethite (a-FeOOH) becomes easily to porous hematite (a- $\mathrm{Fe}_{2} \mathrm{O}_{3}$ ) by roasting process and it has high catalytic activity.

Also, dolomite is widely used as well known cheap natural mineral catalyst for tar conversion [5]. It shows moderate performance and especially good for heavy tar reforming. Dolomite increases the hydrogen production ratio in a steam-gasification gas reforming process 
because of ability of $\mathrm{CO}_{2}$ capture.

In this study, the catalytic behaviors of limonite, dolomite and combination of limonite and dolomite on tar decomposition were studied. Effects of temperatures in tar decomposition process are also discussed.

\section{Experiment}

\section{2-1. Biomass}

The woody biomass has been made of cedar and its bark with a size below $1.4 \mathrm{~mm}$. Before experiment, the biomass sample was dried at $380 \mathrm{~K}$ for $1 \mathrm{~h}$. Sample properties are shown in Table 1. As indicated in Table 1, main component of woody biomass was volatile matter in proximate analysis. The maim components in ultimate analysis were carbon, oxygen and hydrogen.

\section{2-2. Catalysts}

Natural limonite ore (Kyushu Area) has been used as a catalyst. Table 2 shows the elemental analysis of the limonite ore, indicating an iron content as high as $50.9 \%$. The limonite ore is a fine powder with orange color. The main component is goethite ( $\alpha$ $\mathrm{FeOOH}$ ) and a small amount of a soft, gray, talc-like mineral is dispersed heterogeneously. In catalyst preparation, the limonite ore was pulverized and mixed with distilled water $(1: 1, \mathrm{wt} / \mathrm{wt})$. And then it was dried at $380 \mathrm{~K}$ for $24 \mathrm{~h}$. The dried sample was gently crushed and sieved for classifying and taking about 1-2 mm size. The classified limonite ore was heated at $600^{\circ} \mathrm{C}$ and dehydrated for 1 hour in steam with 200 $\mathrm{ml} / \mathrm{min}$ flow rate. This sample had been changed from goethite $(\mathrm{a}-\mathrm{FeOOH})$ to porous hematite $\left(\mathrm{a}-\mathrm{Fe}_{2} \mathrm{O}_{3}\right)$ by this roasting process. We call it limonite catalyst which has high catalytic activity.

Natural dolomite ore with size of 1-2 mm was also used as catalyst. Table 3 shows the elemental analysis of the dolomite ore with a $\mathrm{CaO}$ as high as $34.8 \%$. In catalyst preparation, the dolomite ore was heated and decarboxylated at $900^{\circ} \mathrm{C}$ for 1 hour.

\section{2-3. Apparatus and methods}

Experiments were carried out in a two-stage fixed-
Table 1. Properties of woody biomass.

\begin{tabular}{c|c|c|c|c}
\hline \hline \multicolumn{5}{c}{ Proximate analysis [wt. \%] } \\
\hline Mois. & V.M. & F.C. & Ash \\
\hline 9.7 & 70.5 & \multicolumn{1}{c}{18.2} & 1.7 \\
\hline \multicolumn{5}{c}{ Ultimate analysis [wt. \%, daf] } \\
\hline C & $\mathrm{H}$ & $\mathrm{N}$ & $\mathrm{S}$ & O (diff.) \\
\hline 51.8 & 7.1 & 0.1 & 0.2 & 40.7 \\
\hline
\end{tabular}

Table 2. Limonite ore of components.

\begin{tabular}{l|c|c|c|c|c|c}
\hline \hline & $\mathrm{Fe}$ & $\mathrm{Si}$ & $\mathrm{Ca}$ & $\mathrm{Mg}$ & $\mathrm{Na}$ & $\mathrm{K}$ \\
\hline (wt. \%, d.b) & 50.89 & 2.62 & 1.86 & 0.05 & 0.16 & 0.41 \\
\hline
\end{tabular}

Table 3. Dolomite ore of components.

\begin{tabular}{c|c|c|c}
\hline \hline & $\mathrm{CaO}$ & $\mathrm{MgO}$ & $\mathrm{SiO}_{2}$ \\
\hline (wt. \%, d.b) & 34.8 & 17.8 & 0.4 \\
\hline
\end{tabular}

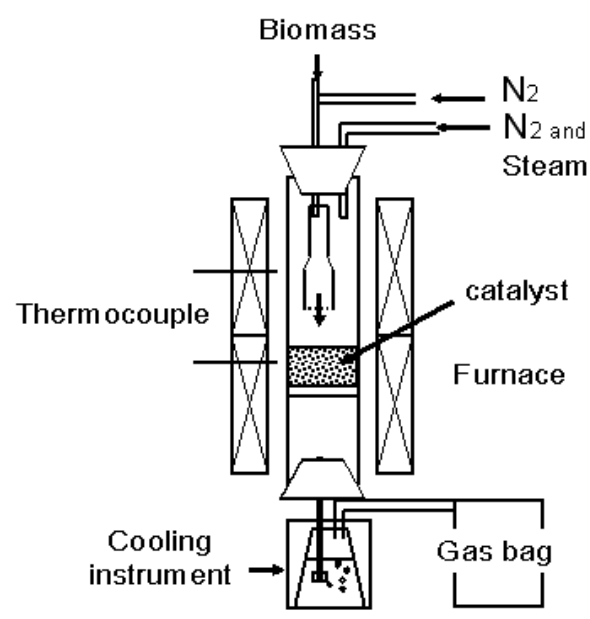

Fig. 1. Schematic diagram of the reaction system.

bed quartz reactor with $30 \mathrm{~mm}$ internal diameter and $900 \mathrm{~mm}$ length. The height of the catalyst bed in the reactor was approximately $50 \mathrm{~mm}$. The schematic diagram of the two-stage, fixed-bed quartz reactor is shown in Fig. 1. Each temperature of two stages was controlled by two electric furnaces.

Firstly, biomass sample of about $1.0 \mathrm{~g}$ was injected and pyrolyzed at $500^{\circ} \mathrm{C}$ in the first reactor, then the produced pyrolysis gases were directly entered to a second reactor with catalysis. The steam catalytic gasification had been carried out at $600-800^{\circ} \mathrm{C}$. Unreacted tar was collected in a condensation system and noncondensed gases were collected with a sample gas bag. The gas samples were analyzed by GC/FID and 
GC/TCD. After gasification, amount of deposited carbon on catalyst was analyzed by combustion method.

\section{Results and discussion}

\section{3-1. Tar decomposition with the limonite and sand}

The carbon conversion yield is one of the most important operation-indicator in tar reforming process. The carbon conversion yield to gases and the component of produced gases at $700^{\circ} \mathrm{C}$ are shown in Fig. 2. In comparing between inert-sand and limonite with high catalytic activity, limonite catalyst promotes tar decomposition only a little, from about $87.6 \%$ to 92.5\%. However hydrogen $\left(\mathrm{H}_{2}\right)$ and carbon dioxide $\left(\mathrm{CO}_{2}\right)$ are almost four times increased. These results show that limonite catalyst has high catalytic activity.

Temperature is an important factor in catalytic reactions. The effect of temperature on the hydropyrolysis of volatile matter was investigated with

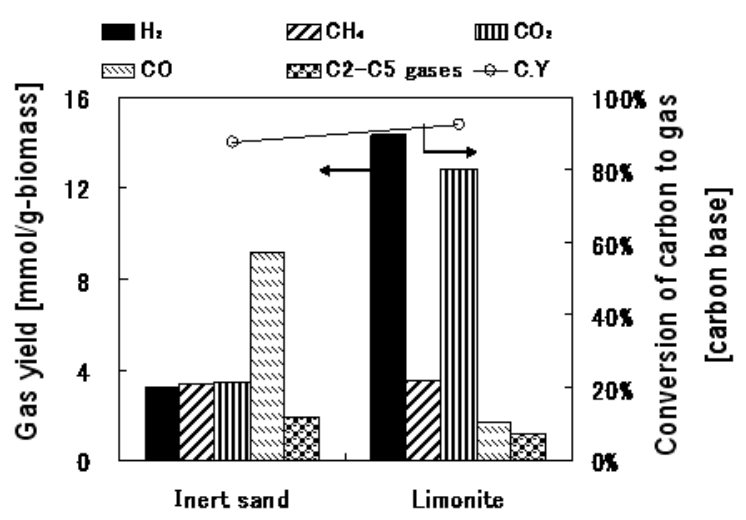

Fig. 2. Effects of limonite on product gas and conversion yield of carbon to gas yields (C.Y) at $700^{\circ} \mathrm{C}$.

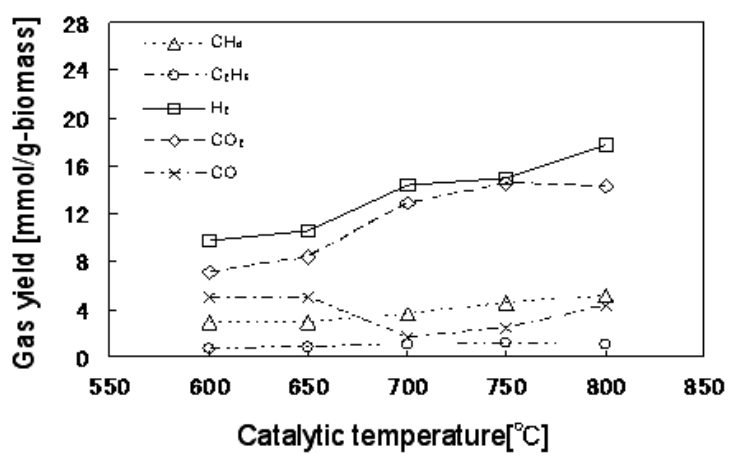

Fig. 3. Effect of temperature on product with limonite. limonite catalyst and shown in Fig. 3. The compositions of $\mathrm{H}_{2}$ and $\mathrm{CO}_{2}$ increased with temperatures increasing. That is, the tar was decomposed (gasification) by the limonite catalyst as shown in Eq. (1). The production yield of $\mathrm{H}_{2}$ and $\mathrm{CO}_{2}$ was increased remarkably and that of $\mathrm{CO}$ was decreased above $650^{\circ} \mathrm{C}$. From these results, the $\mathrm{CO}$ produced from the tar decomposition was converted to $\mathrm{CO}_{2}$ and $\mathrm{H}_{2}$ by the water shift reaction (Eq. (2)).

$$
\begin{aligned}
& \mathrm{Tar}+\mathrm{H}_{2} \mathrm{O} \rightarrow \mathrm{H}_{2}+\mathrm{CO}+\mathrm{CO}_{2}+\mathrm{CmCn} \\
& \mathrm{CO}+\mathrm{H}_{2} \mathrm{O} \rightarrow \mathrm{H}_{2}+\mathrm{CO}_{2}
\end{aligned}
$$

Carbon deposition on catalysts would result into the deactivation of catalysts. The amount of carbon deposition was increased with increasing temperature up to $700^{\circ} \mathrm{C}$. The increasing rate was decreased above $750^{\circ} \mathrm{C}$. It is reason that the carbon deposition was converted to $\mathrm{CO}$ by water gas reaction (Eq. (3)) above $750^{\circ} \mathrm{C}$

$$
\mathrm{C}+\mathrm{H}_{2} \mathrm{O} \rightarrow \mathrm{H}_{2}+\mathrm{CO}
$$

\section{3-2. Catalystic tar decomposition with limonite and dolomite}

The dolomite was gently crushed and sieved for classifying and taking about 1-2 $\mathrm{mm}$ size. This classified dolomite was heated at $900^{\circ} \mathrm{C}$ and calcined for 1 hour in nitrogen with $200 \mathrm{ml} / \mathrm{min}$ flow rate before tar decomposition. After catalystic tar decomposition, catalyst (dolomite) was heated to $830^{\circ} \mathrm{C}$ for determining

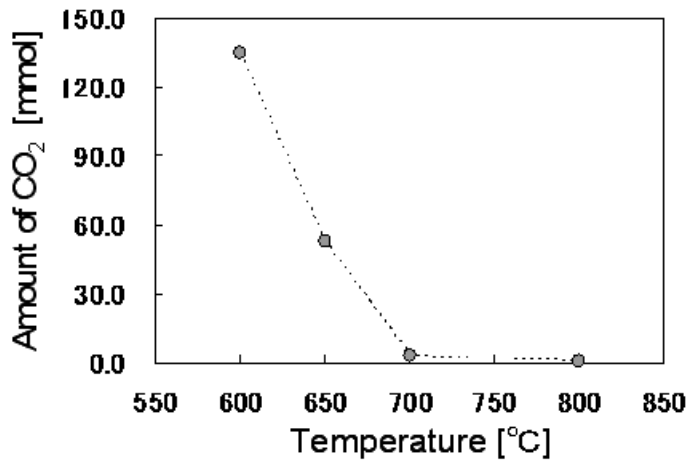

Fig. 4. Amount of $\mathrm{CO}_{2}$ released from dolomite. 


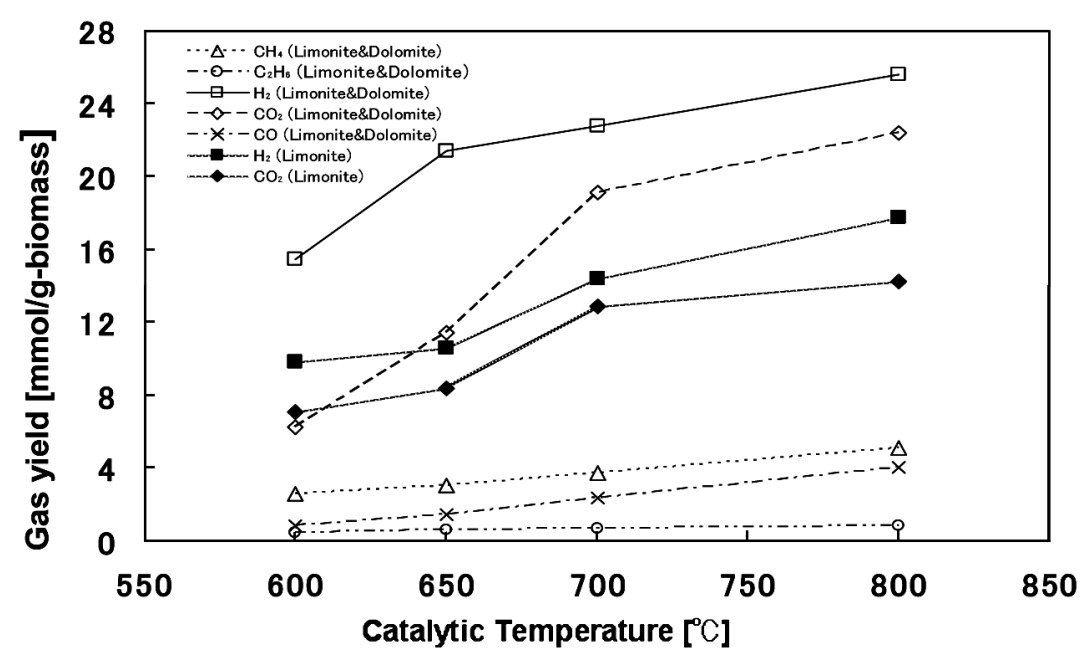

Fig. 5. Effect of temperature on product gas yields with catalyst mixed limonite and dolomite.

the $\mathrm{CO}_{2}$ amount absorbed by dolomite during the gasification. The catalystic tar decomposition with dolomite was done under the same experimental condition at the range $600^{\circ} \mathrm{C} \sim 800^{\circ} \mathrm{C}$. As shown in Fig. 4, the absorbed $\mathrm{CO}_{2}$ amount was decreased with increasing reaction temperature and it became to almost zero at above $700^{\circ} \mathrm{C}$. This result is due to reacting $\mathrm{CaO}$ with $\mathrm{CO}_{2}$ in the tar decomposition reaction and became $\mathrm{CaCO}_{3}$ under the $650^{\circ} \mathrm{C}$.

When we used the catalyst mixed with limonite and dolomite, we got the best hydrogen gas yield and tar conversion rate. The results are shown in Fig. 5. The compositions of $\mathrm{H}_{2}$ and $\mathrm{CO}_{2}$ increased with increasing temperatures. The trend is the same results in the case of limonite only. However, the gas yield of $\mathrm{H}_{2}$ in the case of mixed catalyst was increased about $160 \%$ comparing the only limonite. That is, the tar was easily decomposed (gasification) on mixed (limonite and dolomite) catalyst than limonite only. As another reason, we think that $\mathrm{CO}_{2}$ was absorbed by dolomite under $700^{\circ} \mathrm{C}$ (Fig. 4), and this $\mathrm{CO}_{2}$ absorption promotes reaction of $\mathrm{CO}$ with steam (Eq. (2)) and as a result, hydrogen is more produced.

\section{Conclusions}

The limonite was good catalyst for biomass hydropyrolysis. In the high temperature, water shift reaction and water gas reaction were occurred. Light gases produced from reforming the tar of biomass gasification are mainly hydrogen and carbon dioxide. Hydrogen yields increased with temperature increasing in the range of $650-800^{\circ} \mathrm{C}$, because the water shift reaction was promoted by catalyst. The yield of hydrogen gas was 1.6 times under catalyst with the limonite and dolomite mixture compared to limonite only.

Above results show that the natural limonite and dolomite ores are good catalysts in the tar decomposition light fuel gas production by hydro-pyrolysis of biomass.

\section{Acknowledgments}

The authors would like to thank "The Uchida Energy Science Promotion Foundation" and "Sasaki Environment Tec. Found." for the financial supports.

\section{REFERENCES}

1. Milne TA, Abatzoglou N, Evans RJ. Biomass gasifier "tars": their nature, formation and conversion. National Renewable Energy Laboratory (NREL), reports NREL/ TP-570-25357, Colorado, 1998.

2. J. Delagado, M.P. Aznar and J. Corella, Biomass gasification with steam in fluidized bed: effectiveness of $\mathrm{CaO}, \mathrm{MgO}$ and $\mathrm{CaO}-\mathrm{MgO}$ for hot gas cleaning. Ind Eng Chem Res, 36 (1997), pp. 1535-1543.

3. J. Arauzo, D. Radlein, J. Piskorz and D.S. Scott, Catalytic pyrogasification of biomass. Evaluation of modified 
nickel catalysts. Ind Eng Chem Res, 36 (1997), pp. 67-75.

4. R. Coll, J. Salvado, X. Farriol and D. Montane', Steam reforming model compounds of biomass gasification tars: conversion at different operating conditions and tendency towards coke formation. Fuel Process Technol, 74 (2001), pp. 19-31.

5. D. Lopamudra, J.P. Krzysztof and J.J.G.J. Frans, Pretreated olivine as tar removal catalyst for biomass gasifiers. Fuel Process Technol, 86 (2005), pp. 707-730. 